\title{
Lifetime Estimation for Metal Sheet Cladding and Roofing in Wang-Noi Combined Cycle Power Plant
}

\author{
Chakrit Suvanjumrat $^{1,2, *}$ and Ravivat Rugsaj ${ }^{2}$ \\ 1 Department of Mechanical Engineering, Faculty of Engineering, Mahidol University, Nakhon Pathom \\ 73170, Thailand \\ 2 Laboratory of Computer Mechanics for Design (LCMD), Department of Mechanical Engineering, Faculty \\ of Engineering, Mahidol University, Nakhon Pathom 73170, Thailand \\ *E-mail: chakrit.suv@mahidol.ac.th
}

\begin{abstract}
This research aimed to study corrosion behavior and evaluated lifetime of the metal sheet cladding and roofing when exposed to actual usage environment using electrochemical impedance spectroscopy (EIS) test method. The sample plates were galvanized steel grade 550 and thickness of $0.6 \mathrm{~mm}$ which was coated with $55 \%$ of $\mathrm{Al}-\mathrm{Zn}$ and a polyvinylidene fluoride layer which were prepared for metal sheet cladding and roofing of Wang-Noi combined cycle power plant in Phra Nakhon Si Ayutthaya province of Thailand. The specimens were tested under wet-dry cyclic condition by immersing in the simulated acid rain solution for an hour, then the specimen was removed from the solution and allowed to dry in open air environment with exposing to sunlight for 7 hours a day. The wet-dry cyclic treatment was repeated 3 times a day which was considered as the severe usage condition therefore the 3 wet-dry cycles might lead to extreme corrosion due to raining about 3 times a day. The EIS was used to evaluate the corrosion rate of specimens after the wet-dry cyclic treatment. Analysis results were expressed in Bode and Nyquist plot and used to calculate for corrosion current by using Stern-Garry equation which was used to calculate corrosion rate by using Faraday's law. The first order polynomial regression was appropriate to estimate corrosion rate beyond the real time usage of the metal sheet, and total mass loss over time was estimated by integrating the polynomial regression model to obtain the governing equation of the total mass loss of the cladding and roofing sheet in the usage environment. The evaluated mass loss over 20 years of usage under severe condition was estimated which had the maximum penetration of 1.04004 milli-inch and could be converted into penetrating thickness of $26.41 \mu \mathrm{m}$.
\end{abstract}

Keywords: Lifetime, estimation, cladding, roofing, power plant.

ENGINEERING JOURNAL Volume 20 Issue 2

Received 12 May 2015

Accepted 14 July 2015

Published 18 May 2016

Online at http://www.engj.org/

DOI:10.4186/ej.2016.20.2.147 


\section{Introduction}

The metal sheet favors to use for wall and roof panel system of building of Wong-Noi combined cycle power plant in Phra Nakhon Si Ayutthaya province of Thailand. The metal grade of wall and roof system is accorded to ASTM A792/A792M [1]. An exterior surface of wall and roof system often protects corrosion by specification of coating materials for a minimum life time usage of 20 years in a tropical environment without maintenance. The material and coating layers following the specification may extend the life time of the wall and roof panel system. Unfortunately, they do not confirm the life time usage without maintenance.

Corrosion is a chemical process which causes gradual destruction of metal by reaction to the environment. Atmospheric corrosion is one of the most common forms of metallic corrosion in the natural outdoor atmosphere. The corrosion occurs on a metal that covered with a thin layer of electrolyte form by the presence of relative humidity. The corrosion behavior under a thin electrolyte has been known to be different from the corrosion of metal under bulk solution. A simple test for corrosion measurement is a weight loss method. This method involves cleansing to remove corrosion product and weighting to determine weight loss of the specimen. The corrosion rate can be calculated by defining the loss of weight (per unit area) as a function of time. Although this test is simple, the method can't provide insight into mechanisms of the corrosion to evaluate the lifetime of metal products. Moreover, some corrosion processes occur without the significant mass change (e.g. pitting corrosion) therefore it makes them difficult to detect by these gravimetric methods.

Electrochemical technique such as potentiodynamic polarization method using direct current (DC) might be used to evaluate corrosion rate [2]. This method is based on electrochemical theory because most corrosion phenomenon is the electrochemical nature which consists of reaction on the surface of the corroding metal. Therefore electrochemical test method could be used to characterize corrosion mechanism and predicted corrosion rates [3, 4]. Most of metal corrosion occurs via electrochemical reactions at the interface between the metal and an electrolyte solution. Corrosion normally occurred at a rate which was determined by equilibrium among opposing electrochemical reactions. However, the use of potentiodynamic polarization method to study mechanisms of atmospheric corrosion of a painted or inorganic coated metal is difficult. The presence of painting or inorganic coating and thin layer of electrolyte could be resulted in extremely high resistance. In addition, the error was also occurred from ohmic drop between the reference and working electrodes and uneven current distribution over the working electrode [5-8]. These errors could be compensated by using alternating current (AC) impedance techniques or electrochemical impedance spectroscopy (EIS) method [9]. The polarization resistance might be obtained by subtracting high frequency impedance (solution resistance) from low frequency impedance to compensate the ohmic drop, while the current distribution could be estimated from the EIS results. Recently, the AC impedance technique or EIS method could be used to study an intrusion of water and ions into organic coatings for comparing performance of various inorganic coatings or surface treatments. The EIS method could also be produced models of the solution/inorganic coating/metal system and thus yield mechanistic information about the protective system [10-14].

This research proposed to study corrosion behavior and evaluate lifetime of the metal sheet cladding and roofing when exposed to actual usage environment using electrochemical corrosion test method according to ASTM G5 [15], G59 [16], G96 [17] and G106 [18]. The reaction between galvanized steel and simulated acid rain (SAR) would be occurred through coating surface which was porous layers. The corrosion rate was predicted by EIS method obtained from potentiostat device according to ASTM G3 [19] and G102 [20]. The analyzed penetration and corrosion rate can be used to estimate lifetime of wall and roof panel and help developing standard for testing and designing of wall and roof panel system in the future work of power plant in Thailand.

\section{Experiment}

Rectangular plates were cut from the metal sheet cladding and roofing to prepare for being samples of the corrosion test. The sample plate was galvanized by steel grade 550 and thickness of $0.6 \mathrm{~mm}$ which was coated with 55\% Al-Zn and steel grade 550 according to ASTM A792/A792M. The exterior surface of sample plates was coated with the minimum barrier coating (primer) of 15 micron corrosion resistant high film build primer and the minimum finish coating of 25 micron Polyvinylidene Fluoride (PVDF), while the 
interior surface was coated with minimum barrier coating of 8 micron corrosion resistant high film build primer and the minimum finish coating of minimum 20 micron PVDF. The distinct detail of surface coating of a sample plate is illustrated in Fig. 1. The specimen was cut from samples with the dimension of $2 \mathrm{x} 1 \mathrm{~cm}$ (length $\mathrm{x}$ width) and then abraded with an abrasive paper up to \#2000 and was clean with acetone solution which referred to ASTM G1 [21]. The sample plates and prepared specimens are shown in Fig. 2. The SAR solution was prepared for artificial environment of metal sheet usage. The chemical composition of SAR solution is shown in Table 1 with a $\mathrm{pH}$ of 3.5.

The specimen was tested under wet-dry cyclic condition which was typical treatment of the metal sheet to study corrosion by immersing in solution and exposing to sunlight. The treatment's objective was to simulate atmospheric corrosion as in the working environment of the wall and roof panel system. The specimen was immersed in SAR solution for an hour, and was removed from the solution then allowed to dry in open air environment with exposure to sunlight for 7 hours a day [10-14]. Figure 3 shows a specimen which is immersed in the SAR solution and allowed to be died in open-air environment. The wet-dry cyclic treatment was repeated 3 times a day. The experiment proceeded by the wet-dry cyclic treatment cause of atmospheric corrosion which referred to ASTM G85 [22] and D5894 [23].

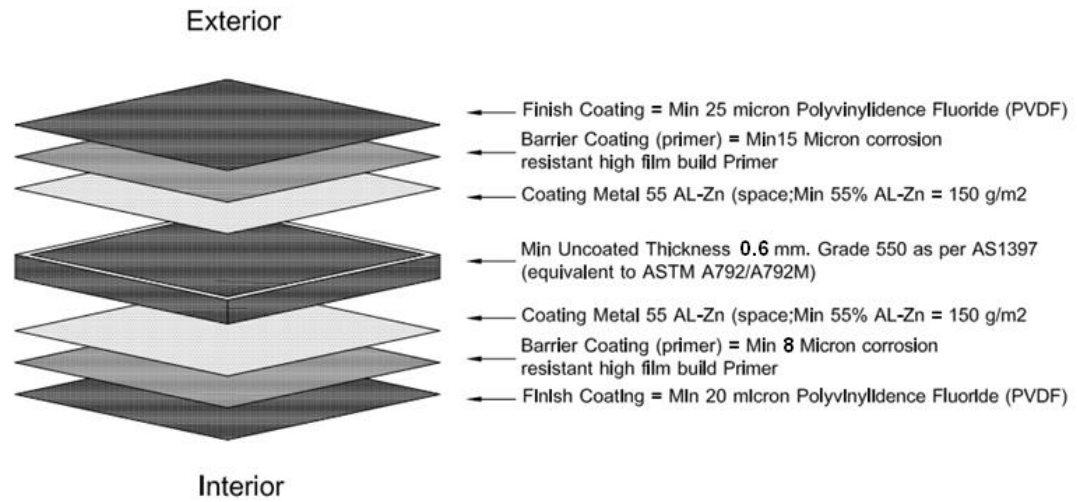

Fig. 1. Detail of surface coating of specimens.

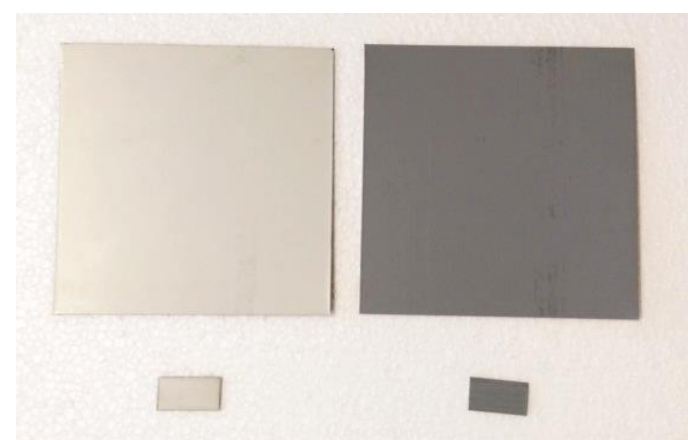

Fig. 2. Samples (top) and prepared specimens (bottom) with outer surface (left) and inner surface (right) of the metal sheet cladding and roofing.

Table 1. The chemical composition of SAR solution [14].

\begin{tabular}{cc}
\hline Ion & Concentration $\left(\mathrm{mg} \mathrm{dm}^{-3}\right)$ \\
\hline $\mathrm{F}^{-}$ & 0.098 \\
$\mathrm{Cl}^{-}$ & 1 \\
$\mathrm{NO}^{-}$ & 7.1 \\
$\mathrm{SO}_{4}{ }^{2-}$ & 11.1 \\
$\mathrm{NH}_{4}$ & 2.3 \\
$\mathrm{Na}^{+}$ & 0.42 \\
$\mathrm{~K}^{+}$ & 0.11 \\
$\mathrm{Ca}^{2+}$ & 0.049 \\
$\mathrm{Mg}^{2+}$ & 0.045 \\
\hline
\end{tabular}




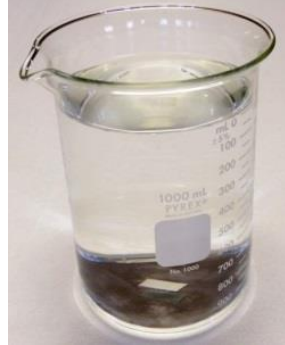

(a)

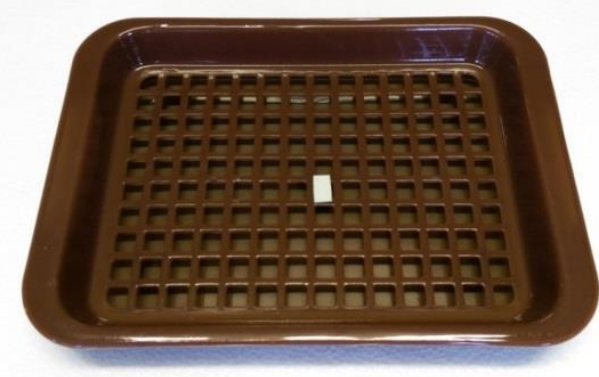

(b)

Fig. 3. Treatment of specimen under wet-dry cyclic condition by (a) immersing specimen in the SAR solution and (b) drying specimen in the open-air environment.

After scheduled time (1 week) the treated specimen was brought to perform electrochemical corrosion test with potentiostat device. The process was repeated on the remaining specimen until final set of the specimen brought to test at the end of study duration ( 8 weeks). Eight sets of treated specimens were immersed in the SAR solution for 1 to 8 weeks which marked as S1, S2, S3, .., S8, respectively. These specimens which waited for corrosion test were kept in silica gel boxes to restrain reaction with environment. External coating of specimens in white and light yellow after treats under wet-dry cyclic condition is shown in Fig. 4. There were no breakages on surface of specimens by visual inspection.

Corrosion testing was performed using a potentiostat apparatus of Princeton Applied Research model Parstat 4000 at Iron and Steel Institute of Thailand (ISIT), Thailand. Detail of corrosion testing equipment is shown in Fig. 5. An electrochemical cell is composed of a glass cylinder with two polypropylene ending plates and apertures to permit the inlet of working electrode, counter electrode, reference electrode, gas inlet and outlet tubes are shown in Fig. 6. The experiment was set for conducting EIS measurement referred to ASTM G59 and G96. The testing procedures may conclude as follows:

(a) The counter electrode and reference electrode were set in the test cell.

(b) Before the test, the internal non-conductive coating of specimen was removed and the external coating was placed outside at the right of the corrosion flat cell which contacted with solution.

(c) Specimen surface was not absolutely flat and a piece of Teflon was needed to support by tightening with a locking screw to avoid the leak solution during the test.

(d) A quarter of liter of SAR solution was poured into electrochemical cell.

(e) When the sample and electrochemical cell were completely set in, the potentiostat was turned on and the software was started. The impedance VS frequency and EIS technique were selected for analysis.

(f) EIS module of potentiostat was a tool to analyze the comparative electrochemical behavior of treated-coating samples. The information of electrode and scanning conditions is described in Table 2.

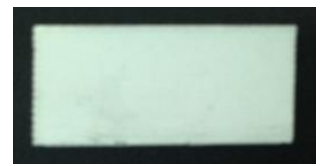

Week 1

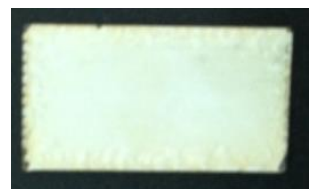

Week 5

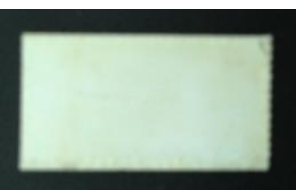

Week 2

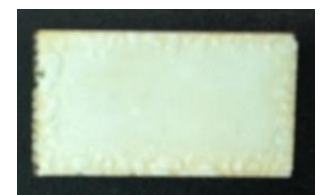

Week 6

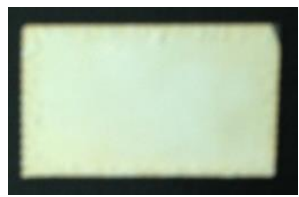

Week 3

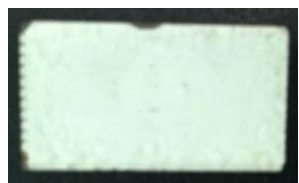

Week 7

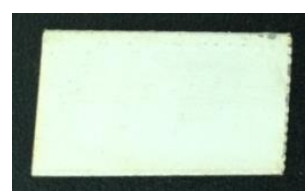

Week 4

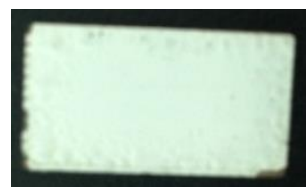

Week 8

Fig. 4. Specimens after treatment under the wet-dry cyclic condition. 


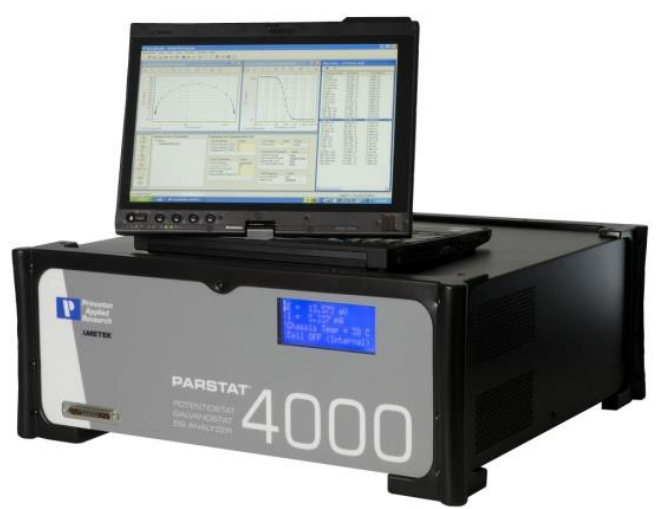

Fig. 5. Potentiostat and galvanostat apparatus of Princeton Applied Reseach model Parstat 4000 at ISIT, Thailand.

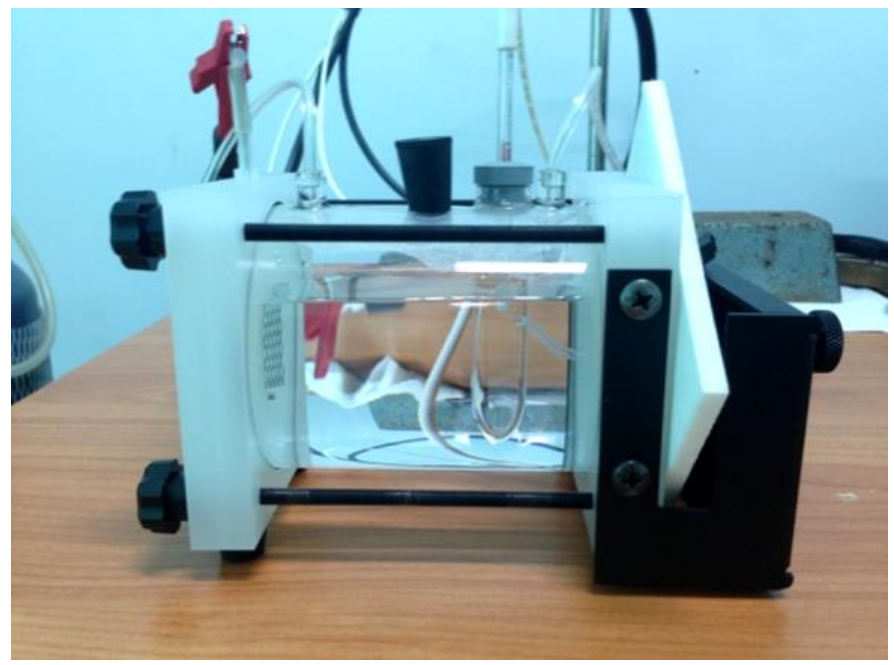

Fig. 6. Set up of an electrochemical corrosion cell.

Table 2. Information of electrode and scanning conditions.

\begin{tabular}{cc}
\hline Operating Parameters & Values \\
\hline Test mode & Potentiostatic EIS \\
Counter electrode & Platinum mesh \\
Reference electrode & $\mathrm{Ag} / \mathrm{AgCl}$ \\
Test temperature & $25^{\circ} \mathrm{C}$ \\
Scan range & $1 \mathrm{MHz}$ to $100 \mathrm{mHz}$ \\
Amplitude & $10 \mathrm{mV}$ \\
\hline
\end{tabular}

Calculation of corrosion rate and mass loss rate by EIS method used corrosion current and potential which was measured. The calculation of corrosion rates and related information from electrochemical measurements was performed according to ASTM G3 and G102. The analysis procedures may conclude as follows:

(a) EIS test used AC signal current with magnitude of $10 \mathrm{mV}$ scanned from high to low frequencies. The testing results were reported in the expression of impedance which composed of a real and imaginary part called as Nyquist plot while impedance and Log frequency plot called as Bode plot.

(b) To calculate the corrosion rate of each specimen, $Z$ simpwin which was electrochemical impedance spectroscopy data analysis software was employed to analyze. A physical phenomenon of Nyquist plots obtained an equivalent electrical circuit model to understand the polarization system of metal sample and its non-conductive coating. All specimens from different treatment conditions were proceeded under the same condition. The fresh solution was replaced after each experiment. 
(c) The corrosion current of each specimen is calculated by using Stern-Garry equation as shown in Eq. (1). The corrosion rate is then obtained by taking $R_{p}$ with known equivalent weight values into the corrosion rate equation as shown in Eq. (2).

$$
\begin{gathered}
R_{p}=\frac{\beta_{\alpha} \cdot \beta_{c}}{2.3 i_{\text {corr }}\left(\beta_{\alpha}+\beta_{c}\right)} \\
C R(m p y)=\frac{0.13 i_{\text {corr }} E W}{\rho}
\end{gathered}
$$

The $R_{p}$ is polarized resistance, $\beta_{\alpha}$ is anodic tafel constant, $\beta_{c}$ is cathodic tafel constant, $i_{\text {corr }}$ is corrosion current, $E W$ is equivalent weight (9) and $\rho$ is density $\left(2.7 \mathrm{~g} / \mathrm{cm}^{3}\right)$

\section{Results and Discussion}

All specimens were tested and analyzed. The average of three specimens from each set was plotted and determined an overlay Nyquist and Bode plot. Figures 7 and 8 show S3 results by Nyquist and Bode plot, respectively. An equivalent circuit for a metal sheet with coating with layers of porous material is illustrated in Fig. 9. This circuit was utilized to enhance the polarization resistance value for the corrosion rate calculation. $\mathrm{R}_{\Omega}$ is the ohmic or uncompensated resistance of the solution between the working and reference electrodes. $\mathrm{R}_{\mathrm{p}}$ is the polarization resistance or charge-transfer resistance at the electrode/solution interface. $\mathrm{C}_{\mathrm{DL}}$ is the double layer capacitance at this interface. The additional circuit elements are the coating capacitance $\left(\mathrm{C}_{\mathrm{C}}\right)$ and resistance of coating pores $\left(\mathrm{R}_{\mathrm{C}}\right)$.

The corrosion rate of each specimen was obtained by taking Rp with known equivalent weight values into the corrosion rate equation as mentioned in earlier. The corrosion current and corrosion rate in the unit of MPY or milli-inch per year of all treated conditions are reported in Table 3. The variation of corrosion rate during wet-dry cycle at each scheduled time (week) along with maximum and minimum value is plotted by the related graph between corrosion rate and time as shown in Fig. 10. The high variation of an obtained data by increasing test time up to 6-8 weeks caused more decimal places of corrosion current for calculating of corrosion rate. Subsequently, the logarithm scale of corrosion rate over time is used to reveal reasonable data and plotted in Fig. 11.

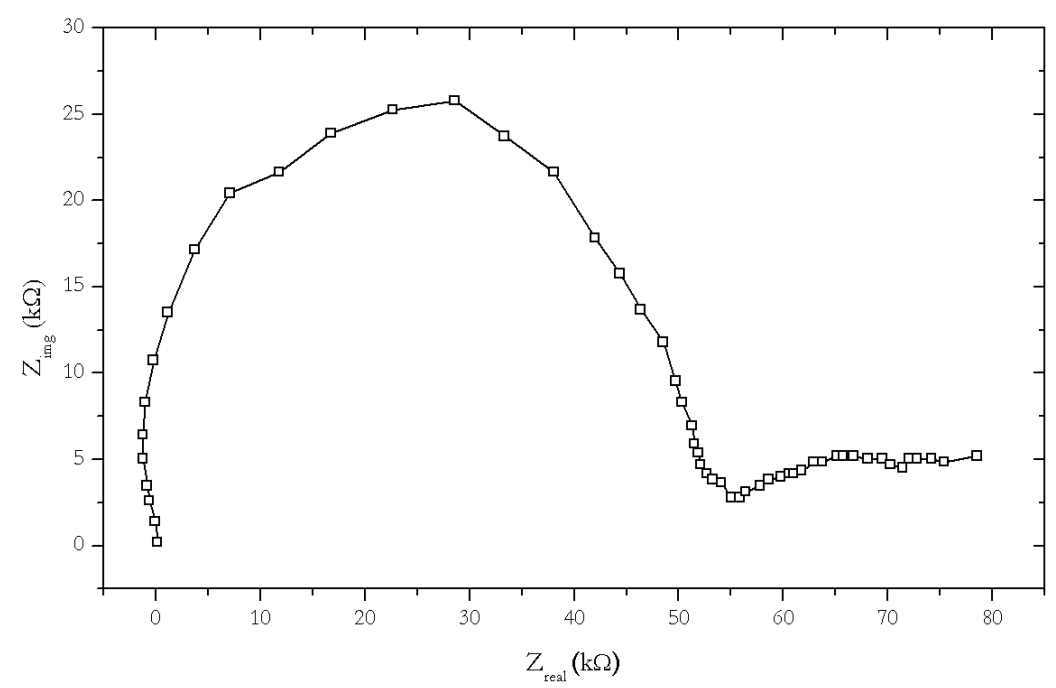

Fig. 7. Nyquist plot by EIS analysis of specimens after 3 week treatment. 


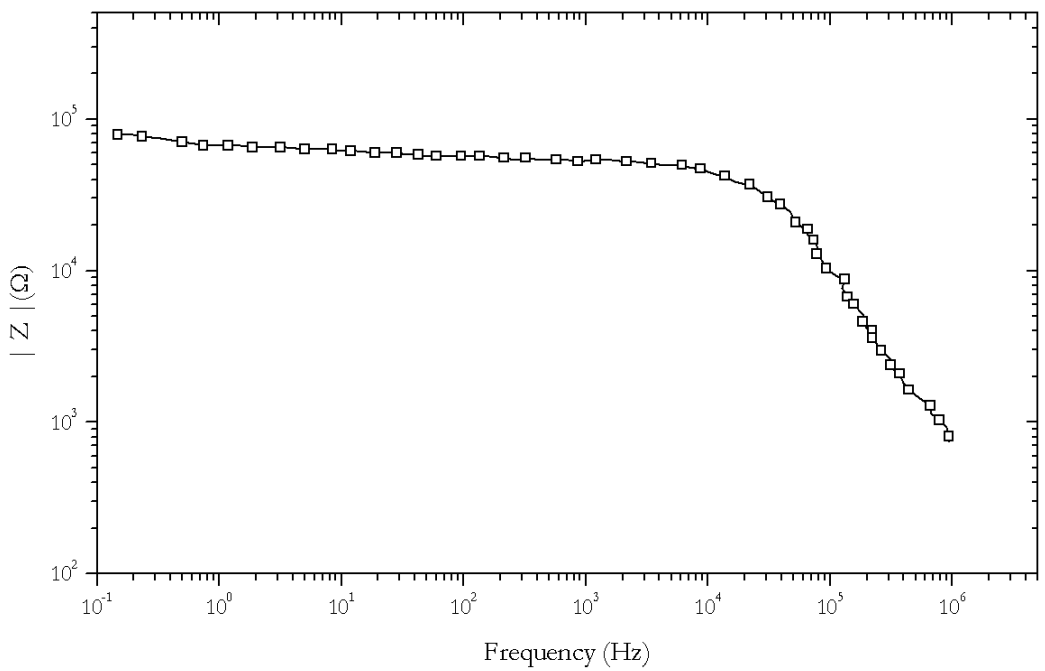

Fig. 8. Bode plot by EIS analysis of specimens after 3 week treatment.

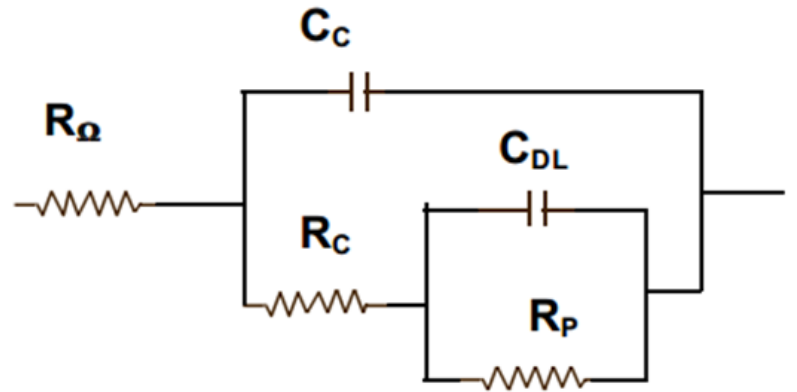

Fig. 9. Equivalent circuit for a metal sheet coating with layers of porous material, non-conductive coating film.

Table 3. Results of EIS tests.

\begin{tabular}{ccccccccc}
\hline $\begin{array}{c}\text { Set of } \\
\text { specimen }\end{array}$ & $\begin{array}{c}\text { Treatment } \\
\text { (week) }\end{array}$ & $\begin{array}{c}\mathbf{R}_{\mathbf{\Omega}} \\
\mathbf{( \Omega )}\end{array}$ & $\begin{array}{c}\mathbf{C}_{\mathbf{C}} \\
(\mathbf{F})\end{array}$ & $\begin{array}{c}\mathbf{R}_{\mathbf{C}} \\
(\mathbf{\Omega})\end{array}$ & $\begin{array}{c}\mathbf{C}_{\mathbf{D L}} \\
\mathbf{( F )}\end{array}$ & $\begin{array}{c}\mathbf{R}_{\mathbf{p}} \\
(\boldsymbol{\Omega})\end{array}$ & $\begin{array}{c}\mathbf{i}_{\text {corr }} \\
(\mathbf{A})\end{array}$ & $\begin{array}{c}\mathbf{C R} \\
(\mathbf{M P Y})\end{array}$ \\
\hline S1 & 1 & $2.34 \mathrm{E}-04$ & $1.20 \mathrm{E}-10$ & $4.29 \mathrm{E}+04$ & $1.65 \mathrm{E}-06$ & $1.37 \mathrm{E}+04$ & $1.58 \mathrm{E}-03$ & $7.67 \mathrm{E}-04$ \\
S2 & 2 & $1.76 \mathrm{E}-04$ & $1.45 \mathrm{E}-10$ & $4.07 \mathrm{E}+04$ & $7.00 \mathrm{E}-07$ & $2.14 \mathrm{E}+04$ & $1.01 \mathrm{E}-03$ & $5.54 \mathrm{E}-04$ \\
S3 & 3 & $1.64 \mathrm{E}-03$ & $1.38 \mathrm{E}-10$ & $5.97 \mathrm{E}+04$ & $1.16 \mathrm{E}-06$ & $3.11 \mathrm{E}+04$ & $7.00 \mathrm{E}-04$ & $5.00 \mathrm{E}-04$ \\
S4 & 4 & $5.26 \mathrm{E}-04$ & $1.02 \mathrm{E}-10$ & $1.14 \mathrm{E}+05$ & $3.75 \mathrm{E}-07$ & $4.68 \mathrm{E}+03$ & $4.64 \mathrm{E}-03$ & $2.13 \mathrm{E}-03$ \\
S5 & 5 & $3.74 \mathrm{E}-03$ & $1.35 \mathrm{E}-10$ & $4.72 \mathrm{E}+04$ & $5.48 \mathrm{E}-06$ & $2.51 \mathrm{E}+03$ & $9.37 \mathrm{E}-03$ & $4.06 \mathrm{E}-03$ \\
S6 & 6 & $7.62 \mathrm{E}-04$ & $1.57 \mathrm{E}-10$ & $5.79 \mathrm{E}+04$ & $5.14 \mathrm{E}-06$ & $3.03 \mathrm{E}+03$ & $7.19 \mathrm{E}-03$ & $3.92 \mathrm{E}-03$ \\
S7 & 7 & $6.68 \mathrm{E}-04$ & $1.49 \mathrm{E}-10$ & $4.52 \mathrm{E}+04$ & $2.37 \mathrm{E}-06$ & $1.97 \mathrm{E}+03$ & $1.10 \mathrm{E}-02$ & $5.66 \mathrm{E}-03$ \\
S8 & 8 & $7.51 \mathrm{E}+00$ & $1.81 \mathrm{E}-10$ & $2.82 \mathrm{E}+04$ & $2.52 \mathrm{E}-06$ & $1.29 \mathrm{E}+03$ & $1.83 \mathrm{E}-02$ & $7.94 \mathrm{E}-03$ \\
\hline
\end{tabular}




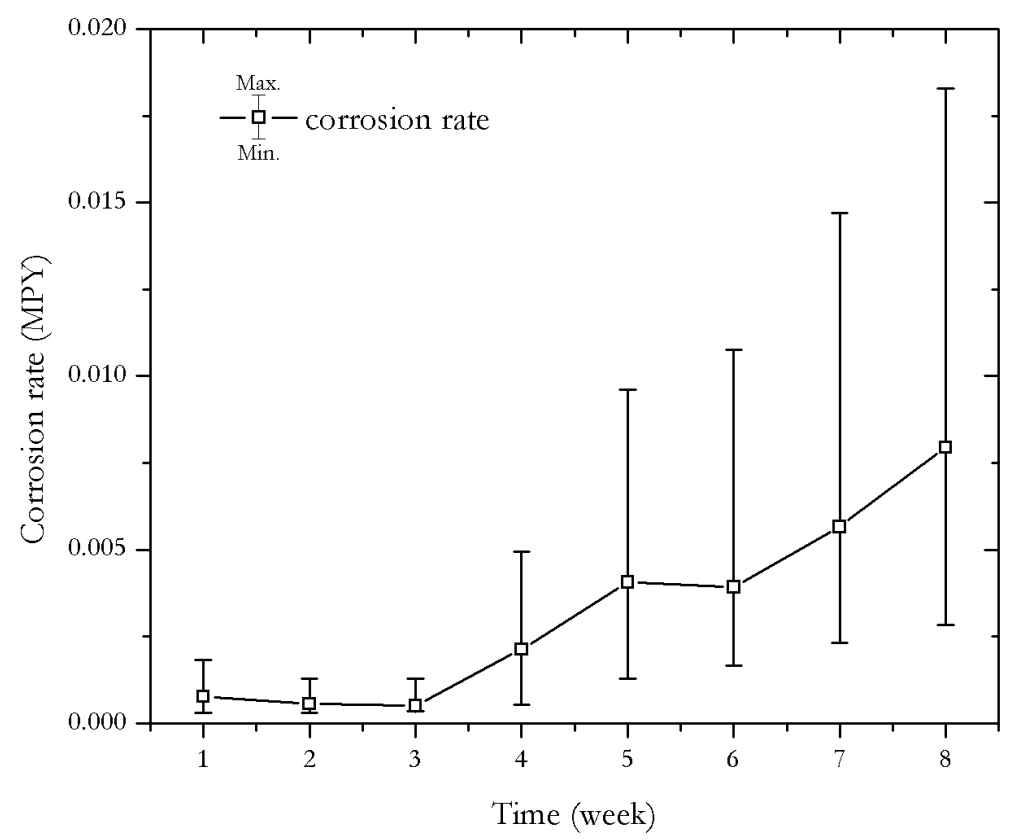

Fig. 10. Corrosion rate during wet-dry cycle at each scheduled time.

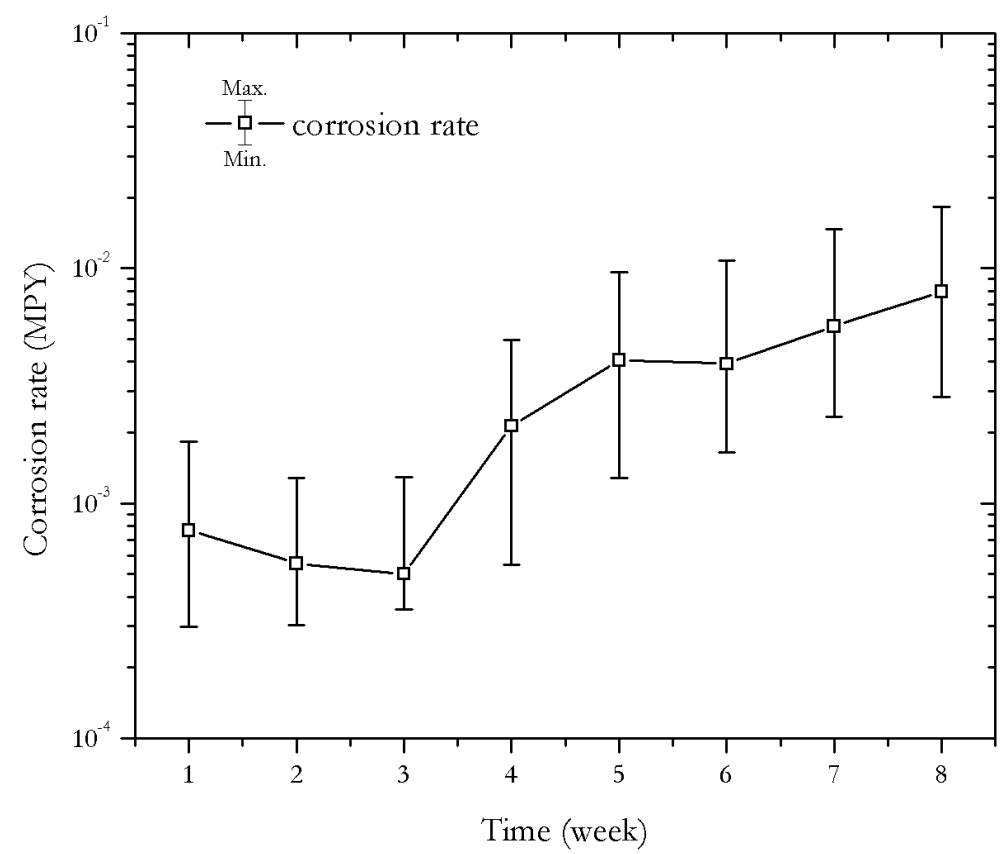

Fig. 11. The logarithm of corrosion rate during wet-dry cycle at each scheduled time.

In order to predict corrosion rate of specimens of the metal sheet cladding and roofing furthering experiment definition, the linear regression was used to fit the experimental result into first order polynomial. The $1^{\text {st }}$ order regression and the experiment data of corrosion rate with time is then plotted and shown in Fig. 12. The corrosion was distinct inside specimens about 1.5 weeks ago. The error estimation by meaning of coefficient of determinant and correlation coefficient is described in Table 4 . The coefficient of determinant $\left(\mathrm{R}^{2}\right)$ obtained 0.9001 , while correlation coefficient $(\mathrm{R})$ was 0.9485 . 


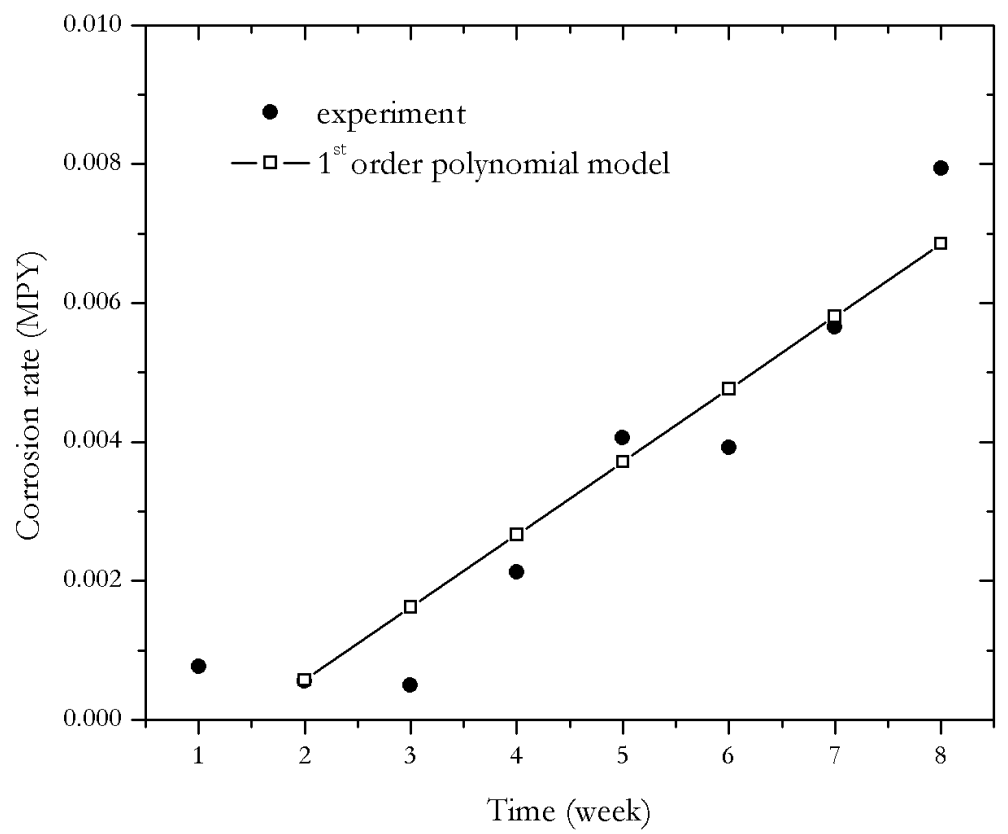

Fig. 12. The 1st order polynomial regression and the experimental result of the corrosion rate with time.

Table 4. Error estimation of linear regression fitting of corrosion rates.

\begin{tabular}{ccc}
\hline \multirow{2}{*}{ Model } & $\begin{array}{c}\text { Coefficient of determinant } \\
\left(\mathbf{R}^{2}\right)\end{array}$ & $\begin{array}{c}\text { Correlation coefficient } \\
(\mathbf{R})\end{array}$ \\
\hline $1^{\text {st }}$ order polynomial & 0.9001 & 0.9485 \\
\hline
\end{tabular}

The $1^{\text {st }}$ order polynomial model was then used to estimate the corrosion rate because it had a good agreement with the actual corrosion rate occurring along the testing time. The regression equation of the $1^{\text {st }}$ order polynomial model is shown the corrosion rate (CR) in the following equation:

$$
C R(\text { mpy })=(1.0468 t-1.5192) \times 10^{-3} \times(1 / 52)
$$

where $t$ is experiment time (weeks).

In order to relate the experiment time to the actual usage time of the metal sheet cladding and roofing which encountered atmospheric corrosion due to acidic raining, the rainy days per year in Phra Nakhon Si Ayutthaya province was referred [24, 25]. The number of rainy days per year in Phra Nakhon Si Ayutthaya province during year 2551 to 2557 B.E. is shown in table 3.

Table 5. Number of rainy days per year in Phra Nakhon Si Ayutthaya province during year 2551 to 2557 B.E. [24, 25].

\begin{tabular}{ccccccccc}
\hline & \multicolumn{7}{c}{ Year (B.E.) } & Average \\
\cline { 2 - 9 } $\begin{array}{c}\text { Rainy days per year } \\
\text { (days) }\end{array}$ & $\mathbf{2 5 5 1}$ & $\mathbf{2 5 5 2}$ & $\mathbf{2 5 5 3}$ & $\mathbf{2 5 5 4}$ & $\mathbf{2 5 5 5}$ & $\mathbf{2 5 5 6}$ & $\mathbf{2 5 5 7}$ & Aver \\
\cline { 2 - 9 } & 117 & 110 & 91 & 92 & 131 & 97 & 112 & 108 \\
\hline
\end{tabular}

The 3 wet-dry cycles or 1 day of experiment was assumed to be 1 rainy day which was considered as the severe condition therefore the 3 wet-dry cycles might lead to extreme corrosion due to raining about 3 times a day. From the assumption, the experiment time may be related to the actual usage time of the metal sheet cladding and roofing during extreme raining per year by Eq. (4).

$$
t(\text { weeks })=\left(\frac{\text { rainy days per year }}{\text { days per week }}\right) \times t_{\text {rainy }}(\text { years })
$$

Substituting average rainy day per year from Table 5 into Eq. (4) obtains Eq. (5).

$$
t(\text { weeks })=\left(\frac{108}{7}\right) \times t_{\text {rainy }}(\text { years })=15.42857 t_{\text {rainy }}(\text { years })
$$


The total mass loss over time could be estimated by integrating Eq. (3). The governing of mass loss (ML) obtains by Eq. (6) and (7), respectively.

$$
\begin{aligned}
M L & =\int(1.0468 t+1.5192) d t \times 10^{-3} \times(1 / 52) \\
M L & =\left(1.0468 \frac{t^{2}}{2}+1.5192 t\right) \times 10^{-3} \times(1 / 52)
\end{aligned}
$$

The mass loss over time for further 20 years by Eq. (7) can be plotted by graph as shown in Fig. 13. The corrosion rate and mass loss for each year along 20 years can be calculated by using Eq. (3) and Eq. (7) which is described in Table 6.

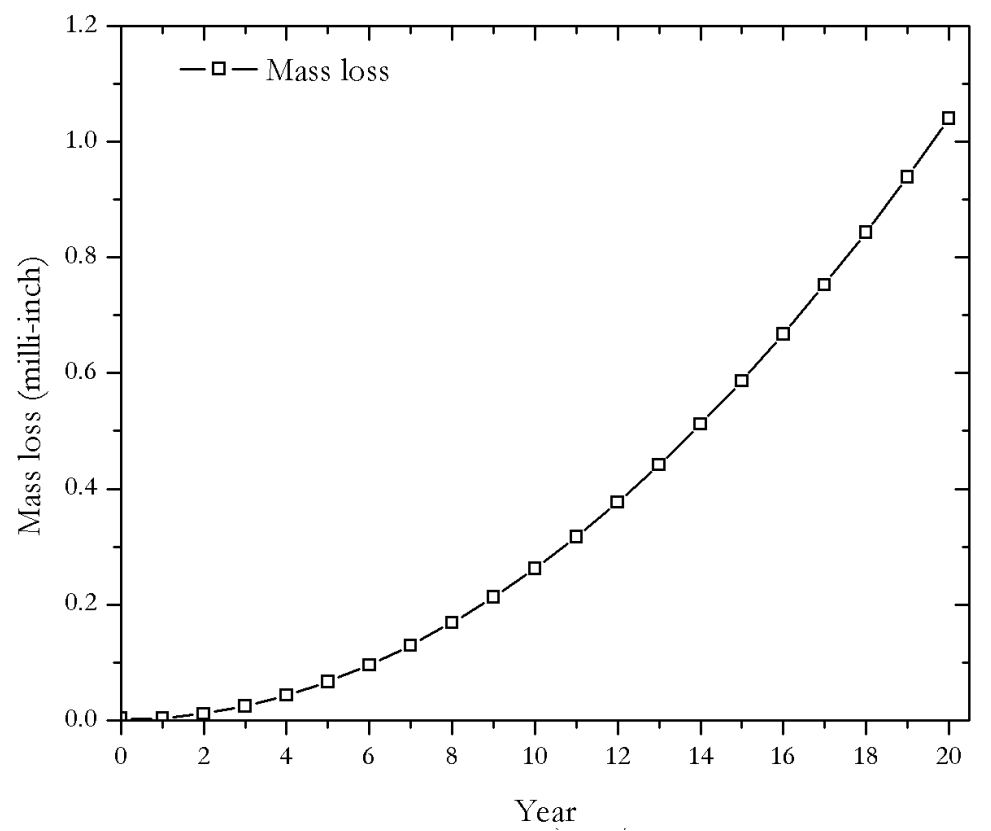

Fig. 13. The total mass loss over time due to atmospheric corrosion by a related graph.

Table 6. The corrosion rate and total mass loss for each year along 20 years due to atmospheric corrosion using Eq. (3) and Eq. (7), respectively.

\begin{tabular}{ccc}
\hline Year & $\begin{array}{c}\text { Corrosion rate } \\
\text { (MPY) }\end{array}$ & $\begin{array}{c}\text { Mass loss } \\
\text { (milli-in) }\end{array}$ \\
\hline 1 & 0.000351308 & 0.003044185 \\
2 & 0.0006734 & 0.011241846 \\
3 & 0.000995492 & 0.024592985 \\
4 & 0.001317585 & 0.0430976 \\
5 & 0.001639677 & 0.066755692 \\
6 & 0.001961769 & 0.095567262 \\
7 & 0.002283862 & 0.129532308 \\
8 & 0.002605954 & 0.168650831 \\
9 & 0.002928046 & 0.212922831 \\
10 & 0.003250138 & 0.262348308 \\
11 & 0.003572231 & 0.316927262 \\
12 & 0.003894323 & 0.376659692 \\
13 & 0.004216415 & 0.4415456 \\
14 & 0.004538508 & 0.511584985 \\
15 & 0.0048606 & 0.586777846 \\
16 & 0.005182692 & 0.667124185 \\
17 & 0.005504785 & 0.752624 \\
18 & 0.005826877 & 0.843277292 \\
19 & 0.006148969 & 0.939084062 \\
20 & 0.006471062 & 1.040044308 \\
\hline
\end{tabular}




\section{Conclusion}

The electrochemical corrosion test was performed on the metal sheet cladding and roofing in order to study corrosion behavior when exposed to actual usage environment. The specimens were tested under a wet-dry cyclic condition by immersing in the SAR solution for an hour and allowed to dry in open-air environment with exposing to sunlight for 7 hours a day in order to simulate atmospheric corrosion and degrade polymer coating as in the working environment of the system. The wet-dry cyclic treatment was repeated 3 times a day which was considered as the severe usage condition therefore the 3 wet-dry cycles might lead to extreme corrosion due to raining about 3 times a day. The EIS method was used to evaluate the corrosion rate of specimens after the wet-dry cyclic treatment. The first order polynomial regression was used to estimate corrosion rate further lifetime usage of the metal sheet cladding and roofing, and the total mass loss over time was estimated by integrating the polynomial regression model to obtain the governing equation of the total mass loss of the cladding and roofing sheet in the usage environment. The evaluated mass loss over 20 years of usage under severe condition was estimated and the maximum penetration was 1.04004 milli-inch. The penetration occurred under coating surface which was on galvanized steel. Therefore, the penetration could be converted into penetrating thickness of $0.02641 \mathrm{~mm}$, which was $4.40 \%$ of an initial metal sheet cladding and roofing thickness (minimum $0.6 \mathrm{~mm}$ ). The evaluation of metal sheet lifetime by EIS method under wet-dry cyclic condition showing the metal sheet cladding and roofing will provide a minimum life of 20 years of usage in a tropical environment without maintenance.

\section{Acknowledgements}

The authors wish to thank Nawarat Pattanakarn Public Company Limited for supporting of sample plates and fund.

\section{References}

[1] Standard Specification for Steel Sheet 55\% Aluminum-Zinc Alloy-Coated by the Hot-Dip Process, ASTM A792/A792M, American Society for Testing and Materials, 2003.

[2] E. McCarfferty, "Kinetics of corrosion," in Introduction to Corrosion Science, $1^{\text {st }}$ ed. New York: Springer, 2010, ch. 7, pp. 118-175.

[3] M. A. Amin, S. S. Abd El-Rehim, E. E. F. El-Sherbini, S. R. Mahmoud, and M. N. Abbas, "Pitting corrosion studies on $\mathrm{Al}$ and $\mathrm{Al}-\mathrm{Zn}$ alloys in SCN- solutions," Electrochim Acta, vol. 54, no. 18, pp. 4288-4296, Jul. 2009.

[4] J. Ma, J. Wen, Q. Li, and Q. Zhang, "Electrochemical polarization and corrosion behavior of Al-ZnIn based alloy in acidity and alkalinity solutions," Int J Hydrogen Energ, vol. 38, no. 34, pp. 14896-14902, Nov. 2013.

[5] E. McCarfferty, "Corrosion under organic coatings," in Introduction to Corrosion Science, $1{ }^{\text {st }}$ ed. New York: Springer, 2010, ch. 13, pp. 402-425.

[6] A. Nishikata, Y. Ichihara, and T. Tsurua, "An application of electrochemical impedance spectroscopy to atmospheric corrosion study," Corros Sci, vol. 37, no. 6, pp. 897-911, Dec. 1995.

[7] A. Nishikata, Y. Yamashita, H. Katayama, T. Tsuru, A. Usami, K. Tanabe, and H. Mabushi, "An electrochemical impedance study on atmospheric corrosion of steels in a cyclic wet-dry condition," Corros Sci, vol. 37, no. 12, pp. 2059-2069, Dec. 1995.

[8] A. Nishikata, Y. Ichihara, and T. Tsurua, "Electrochemical impedance spectroscopy of metals covered with a thin electrolyte layer," Electrochim Acta, vol. 41, no. 7, pp. 1057-1062, May, 1996.

[9] E. McCarfferty, "AC Impedance" in Introduction to Corrosion Science, $1^{\text {st }}$ ed. New York: Springer, 2010, ch. 13, pp. 426-451.

[10] R. P. Vera Cruz, A. Nishikata, and T. Tsuru. "Putting corrosion mechanism of stainless steels under wet-dry exposure in chloride-containing environments," Corros Sci, vol. 40, no. 1, pp. 125-139, Jan. 1998.

[11] S. Magaino, M. Soga, K. Sobue, A. Kawaguchi, N. Ishida, and H. Imai, "Zinc corrosion in simulated acid rain," Electrocbim Acta, vol. 44, no. 24, pp. 4307-4312, Jul. 1999. 
[12] G. A. El-Mahdy, A. Nishikata and T. Tsuru, "Electrochemical corrosion monitoring of galvanized steel under wet-dry conditions," Corros Sci, vol. 42, no. 1, pp. 183-194, Jan. 2000.

[13] A. P. Yadav, A. Nishikata, and T. Tsuru, "Electrochemical impedance study on galvanized steel corrosion under cyclic wet-dry conditions-influence of time of wetness," Corros Sci, vol. 46, no. 1, Jan. 2004.

[14] G. A. El-Mahdy and K. B. Kim, "AC impedance study on the atmosphere corrosion of aluminium under periodic wet-dry conditions," Electrochim Acta, vol. 49, no. 12, pp. 1937-1948, May 2004.

[15] Standard Reference Test Method for Making Potentiostatic and Potentiodynamic Anodic Polarization Measurements, ASTM G5, American Society for Testing and Materials, 1999.

[16] Standard Test Method for Conducting Potentiodynamic Polarization Resistance Measurements, ASTM G59, American Society for Testing and Materials, 2003.

[17] Standard Guide for On-Line Monitoring of Corrosion in Plant Equipment (Electrical and Electrochemical Methods), ASTM G96, American Society for Testing and Materials, 2001.

[18] Standard Practice for Verification of Algorithm and Equipment for Electrochemical Impedance Measurements, ASTM G106, American Society for Testing and Materials, 1999.

[19] Standard Practice for Conventions Applicable to Electrochemical Measurements in Corrosion Testing, ASTM G3, American Society for Testing and Materials, 1999.

[20] Standard Practice for Calculation of Corrosion Rates and Related Information from Electrochemical Measurements, ASTM G102, American Society for Testing and Materials, 1999.

[21] Standard Practice for Preparing, Cleaning, and Evaluating Corrosion Test Specimens, ASTM G1, American Society for Testing and Materials, 2003.

[22] Standard Practice for Modified Salt Spray (Fog) Testing, ASTM G85, American Society for Testing and Materials, 2003.

[23] Standard Practice for Cyclic Salt Fog/UV Exposure of Painted Metal, (Alternating Exposures in a Fog/Dry Cabinet and a UV/Condensation Cabinet), ASTM D5894, American Society for Testing and Materials, 2010.

[24] National Statistical Office. (2015). Statistics of rainfall at meteorology station, Phra Nakhon Si Ayutthaya Province: 2551-2557. [Online]. Available: http://www.nso.go.th/ [Accessed: March 13, 2015].

[25] Ayutthaya Meteorological Station. Statistics of rainfall at meteorology station, Phra Nakhon Si Ayutthaya Province: 2551-2557. [Online]. Available: http://www.tmd.go.th/province.php?id=41 [Accessed: March 13, 2015]. 